\section{¡Recórcholis, Batman!: el : el legado del personaje de : Adam West en el cine de : Burton y de Schumacher:} Recorcholis, Batman!: Adam West : character's legacy in Burton and : Schumacher's cinema :

Romina Angulo ${ }^{1}$, Giancarlo Fernández ${ }^{2}$, Ángeles Licas ${ }^{3}$ ： Sara López ${ }^{4}$, Rocío Rojas ${ }^{5}$ :

\section{Resumen}

El personaje de Batman apareció por primera vez publicado en 1939 y se caracterizó por ser un héroe nocturno en un mundo lleno de color. El presente texto intenta explorar si la adaptación televisiva de 1966 ha tenido una fuerte influencia en la propuesta cinematográfica de las películas del héroe alado dirigidas por Tim Burton y por Joel Schumacher. Se toma como eje lo plástico y la construcción de los personajes, pero también el aporte estético de los directores: la oscuridad en : el caso de Burton o la exageración en las películas de Schumacher.

\section{Abstract}

Batman character first appeared in 1939 and was characterized as a night hero in a full world of color. This article attempts to explore if 1966's television adaptation has a strong influence on cinematographic proposal's of films directed by Tim Burton and Joel Schumacher, with emphasis on plastic proposal and construction of characters, but also in aesthetic contribution of film directors: the darkness or the exaggeration.

\section{Palabras clave}

Batman; televisión; Tim Burton; Joel Schumacher; Adam West; personajes

\section{Key words}

Batman; television; Tim Burton; Joel Schumacher; Adam West; characters

1. Universidad Peruana de Ciencias Aplicadas, Programa Académico de Comunicación Audiovisual y Medios Interactivos, e-mail: rominaangulo13@gmail.com

2. Universidad Peruana de Ciencias Aplicadas, Programa Académico de Comunicación Audiovisual y Medios Interactivos, e-mail: giancarlo2001fernandez@gmail.com

3. Universidad Peruana de Ciencias Aplicadas, Programa Académico de Comunicación Audiovisual y Medios Interactivos, e-mail: 937022371angeles@gmail.com

4. Universidad Peruana de Ciencias Aplicadas, Programa Académico de Comunicación Audiovisual y Medios Interactivos, e-mail: micalop99@gmail.com

5. Universidad Peruana de Ciencias Aplicadas, Programa Académico de Comunicación Audiovisual y Medios Interactivos, e-mail: brirocio200@gmail.com scrupulos

Volumen 7

Número 2

Julio a diciembre 2019

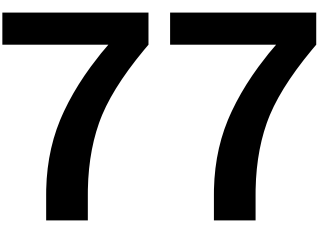

Citar como:

Angulo, R., Fernández,

G., Licas, A., López,

S., Rojas, R. (2019).

¡Recórcholis, Batman!: el

legado del personaje de

Adam West en el cine de

Burton y de Schumacher.

CineScrúpulos, 7(2), 77-82.

DOI: https://doi.

org/10.19083/

cinescrupulos.v7i2.1262

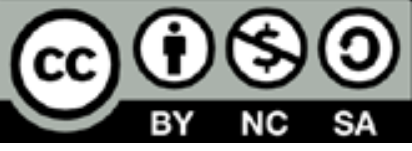

Recibido:

6 de julio de 2019

Aceptado:

23 de setiembre de 2019

Publicado:

9 de diciembre de 2019 
scrupulos

Volumen 7

Número 2

Julio a diciembre 2019

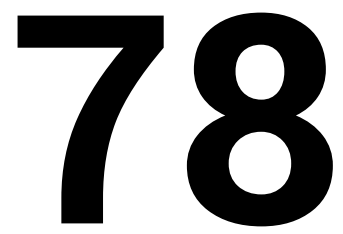

: Es importante preguntarse qué es lo que hace héroe a Batman,

: así como explorar su esencia y el sacrificio que realiza. En el caso - del Batman interpretado por Adam West en "Batman" (Semple Jr., : Kane y Butler, 1966), se plantea un héroe que aboga por los bue- nos valores de la sociedad. Podemos ver un Batman que no bebe - alcohol si va a manejar, cuida al resto de ciudadanos, apoya a su : sobrino en sus estudios e inculca en todo momento las leyes de la - ciudad. La construcción de personajes, tanto de héroes como de : villanos, es unidimensional: o son buenos y quieren practicar el - bien o son malos porque disfrutan del caos y de la atención que : ello les brinda. Por eso no encontramos un conflicto de dualidad : entre el bien y el mal, a pesar de que existen factores que lo hacen dudar de su rol como héroe.

$\bullet$

- Sin embargo, el murciélago tiene un rasgo esencial que lo define : como héroe: está una búsqueda de la llamada "justicia verdadera", : ayuda a la policía y no soluciona las cosas con sus propias manos. - En otras palabras, Batman no asesina a los villanos ni los ataca : antes de que cometan el crimen ya que deja que el sistema judi- cial se encargue de ellos. Es como si se tratara de un ayudante de - la justicia. Estas características también podemos encontrarlas en : "Batman Forever" (Schumacher, 1995) con Dos Caras y El Acertijo, - así como en "Batman" (Burton, 1989) y en "Batman Returns" (Bur: ton, 1992) con Guasón y Pingüino, respectivamente. No obstante, : el Batman de Tim Burton presenta un dilema moral cuando en- cuentra al asesino de sus padres: o cumple su venganza o lo lleva ante la justicia.

MALO POR DECISIÓN

$\bullet$

: Los villanos cumplen un rol muy importante en la narrativa ya que - balancean la historia y aportan dinamismo como las antítesis del : héroe. El personaje de Joker, tanto en la serie de televisión como El personaje de Joker, tanto en la serie de televisión como en las películas de Burton, se representa con una locura exagerada que lo conmina a dañar la sociedad por medio de alucinógenos y demás artilugios. Él no se ensucia las manos a menos que sea necesario.

-

-

- y demás artilugios. Él no se ensucia las manos a menos que sea - necesario. Controla a las personas y las convierte en sus secuaces,

- saca el mal de quienes le rodean y como todo es una fiesta les hace - pensar que es divertido dañar a los demás. Cada acto maligno lo - vive como si fuera una broma y no transmite la crudeza que im- plica la acción de matar. Incluso sus diálogos y movimientos son - dinámicos y cómicos, acompañados de una banda sonora jocosa.

- Esto es común en ambas versiones.

: Pingüino, por otra parte, es una persona de pequeña estatura, nariz - larga, piernas chuecas y las manos siempre enfundadas en guantes. : Es un personaje atípico. En la serie de televisión imita los sonidos - de esta ave y salta de un lado hacia el otro de forma bastante cómi: ca. Esto cambia en la visión de Burton ya que el cuerpo del villano 
se justifica como una deformación de nacimiento y ello permite : otro acercamiento al personaje. No se trata de alguien que busca el mal por placer sino por venganza. Es un villano con motivos, no unidimensional como sí lo es en la serie. Por ello el espectador empatiza con él: porque es un forastero al igual que el personaje principal de "Edward Scissorhands" (Burton, 1990). En la serie de : televisión suele vestir con esmoquin y anda con una pipa, por lo que representa una persona de clase alta. En la película no brinda ese aspecto al inicio ya que se trata de una persona que vive bajo : tierra pero procede de una familia adinerada que, al notar las deformaciones de su hijo, decide lanzarlo a las alcantarillas.

El Acertijo es un villano sigiloso. Al momento de dejar pistas en cada crimen nadie se percata de ello. Solamente Batman logra : atraparlo. Sin embargo, en ambos casos es torpe y excéntrico, hace las cosas a su manera e incluso juega con la ley. En la película de Schumacher aborda, además, un lado más vil. Su caracterización es muy parecida a la de la serie y tiene como accesorios un bastón y su antifaz. Además, El Acertijo de la serie es homenajeado cuando aparece un muñeco en el escritorio de Jim Carrey.

\section{PALABRA Y COLOR}

Los diálogos en las tres adaptaciones revisadas mantienen el carácter de cada propuesta. En la serie de televisión el héroe de Adam West hace uso de elementos narrativos infantiles y lúdicos. Robin dice: "iRecórcholis, Batman!" sin que suene a grosería. Cuando Bruno Díaz le da la réplica, lo hace amenamente. Los diálogos carecen de palabras obscenas o violentas y las palabras se pronuncian exageradamente en cada oración, casi de forma melódica. Las conversaciones son aleccionadoras, tienen ritmo y son recitadas por los personajes. A ello ayuda el uso de las onomatopeyas.

Pero hay un contraste con la mirada de Schumacher: él toma como referencia la serie pero sus diálogos están cargados de sáti- : ra al exagerar ciertas características de los personajes a la hora de hablar o cuando pone en contraposición dos escenas opuestas, lo que provoca risas o extrañeza en el espectador. Por ejemplo, cuando se presenta Batman la atmósfera está cargada de un ambiente heroico, él camina hacia la cámara con su capa que ondea hasta que abruptamente aparece Alfred y le dice: "Un emparedado sería : su mejor acompañante" mientras se lo ofrece con una taza de té.

En el caso del tratamiento del color y de la iluminación, la serie de televisión de los años sesenta presenta altos contrastes y destaca la variación de los colores tanto en los ambientes como en los trajes de héroes y villanos. La colocación de las luces para presentar personajes y escenarios sin dejar espacios en sombra permite un mayor detalle de los lugares donde suceden las escenas. Los

\section{SGRUPULOS}

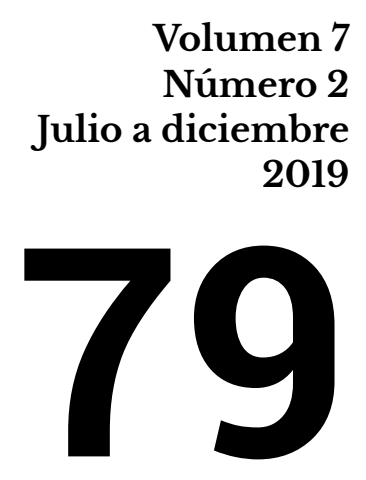

En la serie de televisión el héroe de Adam West hace

uso de elementos narrativos infantiles

y lúdicos. Robin dice: "¡Recórcholis,

Batman!" sin que

suene a grosería. Cuando Bruno Díaz le da la réplica, lo hace amenamente. 
scrupulos

Volumen 7

Número 2

Julio a diciembre 2019

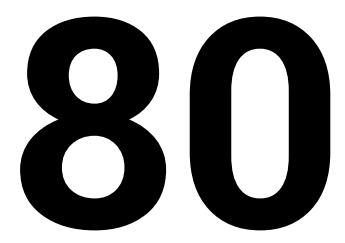

Burton utiliza la

iluminación con

altos contrastes en

luces y sombras

para presentarnos

Ciudad Gótica no

solo como el lugar

donde se narran las

situaciones, sino

como un personaje

importante que

resalta el rostro

oculto de una

sociedad llena

de delincuencia,

prostitución y

suciedad.
: colores en la serie tienen el ambiente sesentero de la época, con

: tonalidades chillonas en los escenarios y en el atuendo de los per: sonajes. Esto quiere decir que tiene un contraste alto, marcado por : el color o el tono.

: Por otro lado, el Batman de Tim Burton toma un rumbo más os: curo, característica inherente a la visión del director que está in- fluenciado por el expresionismo alemán. Burton utiliza la ilumi: nación con altos contrastes en luces y sombras para presentarnos - Ciudad Gótica no solo como el lugar donde se narran las situa: ciones, sino como un personaje importante que resalta el rostro : oculto de una sociedad llena de delincuencia, prostitución y sucie- dad. El uso de luces bajas y la predominancia de altos contrastes : permiten presentar un Batman envuelto en un ambiente de oscu- ridad. La música de Danny Elfman es la cereza en el pastel porque - marca la atmósfera del personaje alado. En este caso también hay : un alto contraste, pero en lugar de utilizar el color usa las luces y sombras en un ambiente desaturado.

La puesta en escena de Schumacher combina la adición de las sombras pronunciadas del cine de Tim Burton con un alto contraste de colores primarios en los escenarios nocturnos, lo que delata la influencia de la serie de los sesentas. Durante las escenas diurnas : hay una saturación de colores más fuertes como el amarillo y el - naranja. De esta forma en los tres casos existe un alto contraste, sea de color, de luz o de ambos.

iPUM!, iPAM!... Y iZAP!

En cuanto a las escenas de acción y a la estética que se usa, es ne- cesario comprender lo que percibimos como violencia tanto en - la serie de televisión como en las películas vistas. En todo caso, : la violencia es entendida como el uso de la fuerza para conseguir un fin, especialmente para dominar a alguien o imponer algo de orden ideológico, sexual, económico o cultural. Bajo esta premisa, : podemos afirmar que en las tres películas se presentan actos de - violencia que son tratados de diferente manera a nivel plástico.

:

En la serie de televisión las peleas son acompañadas por globos de : sonido y onomatopeyas que proceden de los cómics como "iKa: boom!", “iAwk!” o "iClunk-eth!”. Esto causa que los actos violentos : se tomen de forma cómica y ligera. En efecto, los personajes lu: chan y vierten cierto esfuerzo, pero se parece más al slapstick cómico y se convierte en un medio para causar emoción y risas.

En cuanto a la propuesta de Burton, la violencia se presenta con - rasgos de comedia pero añade un estilo más gráfico en cuanto a : los asesinatos y a las escenas de peleas, como cuando se presentan : momentos de sadismo en Joker o cuando Pingüino impone po- 
der. Por el lado de Schumacher, inserta un subcontexto sexual con : los personajes femeninos o sexualiza a Batman mediante su traje : y la aparición de pezones como texturas.

Por otro lado, quizás debido al estilo de los directores, el cigarro y el alcohol son elementos normalizados y el humo se convierte : en parte de la atmósfera de Ciudad Gótica. Las semejanzas en la : caracterización de los personajes varían según el ojo cinematográ- : fico de los tres directores. En las películas de Tim Burton, Batman : sigue siendo un hombre rico y caritativo que quiere hacer el bien porque la justicia no llegó cuando él la necesitaba, pero se le aña- : de un carácter más gótico. Utiliza además un traje que tiene sus proporciones pero es más tieso, duro y de colores oscuros para camuflarse entre las sombras. $\mathrm{Al}$ respecto, aparece la imagen de una gárgola en la ciudad y en las demás construcciones de concreto oscuro. Schumacher, por otro lado, plantea un Batman con rasgos más parecidos a los de Adam West. Incluso en su rol de Bruno Díaz brinda sabiduría a sus empleados, se convierte en padre adoptivo y trata de cuidar y de proteger a Robin, como en la serie. Inclusive : Batman carga con toda la responsabilidad y se sacrifica por Robin : para que no cometa un crimen que en el futuro lo perjudicará.

\section{CONCLUSIÓN}

Las tres propuestas revisadas exponen al personaje de Batman como un civil sin poderes que gracias a su dinero protege su ciudad de cualquier villano que la ponga en riesgo. Tanto Tim Burton como Joel Schumacher rescatan la esencia de los personajes de la serie de televisión de los años sesenta, a pesar de presentar puntos de vista diferentes en el desarrollo de sus historias. Del mismo : modo, tienen en consideración el contraste como medio plástico primordial que aporta un elemento estético tanto en la serie como en los films. Podemos concluir que la serie tiene una influencia en las películas, pero cada director añade su visión cinematográfica: Tim Burton decora la ciudad con un aspecto expresionista y Schumacher retorna a la atmósfera sesentera con mayor exageración en la gama de colores y en la caracterización de los villanos.

\section{SGRUPULOS}

Volumen 7

Número 2

Julio a diciembre

2019

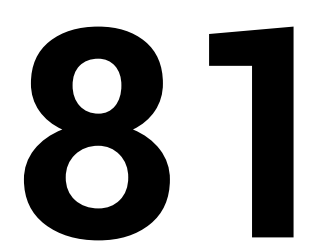

\section{Tanto Tim Burton como Joel \\ Schumacher rescatan \\ la esencia de los personajes de la serie de televisión de los años sesenta, a pesar de presentar puntos de vista diferentes en el desarrollo de sus historias.}


SCRupuLOS

\section{Volumen 7}

Número 2

Julio a diciembre 2019

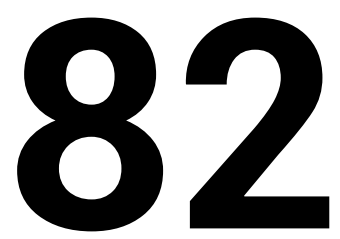

\section{: Referencias}

- Sin el aporte de otras visiones, difícilmente uno puede imaginarse la trilogía de Bat- man firmada por Christopher Nolan y considerada una de las mejores adaptaciones - cinematográficas de algún personaje de comic. Por ello es bueno revisar los an- tecedentes, así el paso del tiempo no haya sido del todo benevolente.

Semple Jr., L., Kane, B. (Guionistas) y Butler, R. (Director). (1966) Hi Diddle Riddle [capítulo de serie de televisión]. En Dozier, W. (Productor), Batman. Estados Unidos: Greenway Productions y 20th Centu-

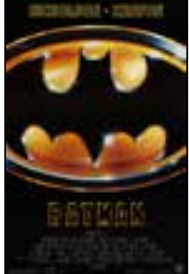

Guber, P., Peters, J. (Productores) y Burton, T. (Director). (1989). Batman [Película]. Estados Unidos e Inglaterra: The Guber-Peters Company.

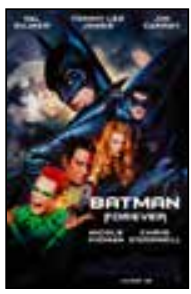

Burton, T., Macgregor-Scott, P. (Productores) y Schumacher, J. (Director). (1995). Batman Forever [Película]. Estados Unidos e Inglaterra: Warner Bros. y PolyGram Filmed Entertainment.
¡Recórcholis, Batman!: el legado del personaje de Adam West en el cine de Burton y de Schumacher

- Referencia del artículo en APA: Angulo, R., Fernández, G., Licas, A., López, S., Rojas, R. (2019). iRecórcholis, Batman!: el legado del personaje de Adam West en el cine de Burton y de Schumacher. : CineScrúpulos, 7(2), 77-82.
Recorcholis, Batman!: Adam West character's legacy in Burton and Schumacher's cinema

Article reference in APA: Angulo, R., Fernández, G., Licas, A., López, S., Rojas, R. (2019). Recorcholis, Batman!: Adam West character's legacy in Burton and Schumacher's cinema. CineScrúpulos, 7(2), 77-82.

CineScrúpulos / Revista digital de diálogo cinematográfico/ ISSN: 2709-0493

- (c) Los autores. Este artículo es publicado por la revista CineScrúpulos del Programa

- Académico de Comunicación Audiovisual y Medios Interactivos de la Facultad de

- Comunicaciones, Universidad Peruana de Ciencias Aplicadas. Este es un artículo de

- acceso abierto, distribuido bajo los términos de la LicenciaCreativeCommons Atribución-

- Compartirlgual 4.0 Internacional (http://creativecommons.org/licenses/by-sa/4.0/), que

- permite el uso no comercial, distribución y reproducción en cualquier medio, siempre que

- la obra original sea debidamente citada. 